\title{
TO MASK OR NOT TO MASK: ASSESSING THE IMPORTANCE OF COLLECTIVE SOCIAL BEHAVIOUR IN RESPONSE TO CRISES IN THE CASE OF COVID-19
}

\author{
Manya Dass \\ Modern School Barakhamba Road, New Delhi \\ DOI: 10.46609/IJSSER.2021.v06i07.032 URL: https://doi.org/10.46609/IJSSER.2021.v06i07.032
}

\section{ABSTRACT}

It is apparent that the Covid-19 pandemic has fundamentally changed the way in which societies across the world are functioning. As countries continue to battle the virus in subsequent waves, it is key to re-evaluate the measures which have been implemented and assess whether they have been successful. Among the most important measures is that of changing collective social behavior, in the form of social distancing, wearing masks, using sanitisers, etc. Despite the available information however, there have been several issues with noncompliance among the populace, especially in countries like India. This paper assesses the theoretical foundations of collective social behavior in response to situations of crisis and contextualises the theories in the Indian context. Analysing the particular cultural context of India, the paper stresses the importance of good collective social behavior, examines what could have been improved, and poses policy recommendations for better enforcement of such behavior through effective public policy enforcement.

\section{Introduction}

Over the past year, the covid-19 pandemic has taken over the world in an unprecedented manner. As of the latest data, world wide cases have crossed over 158 million, with more than 3 million deaths (Worldometer, 2021). Countries such as India are also experiencing deadly second waves of the virus, with multiple shortages in key medicines and drugs, hospital infrastructure and oxygen. Given the effects of the pandemic on public health, the economy and every part of life, it has become apparent that there is great importance to adopt multiple dimensions of response, including governmental, societal, individual, corporate, to manage a large scale pandemic and prevent future pandemics. Due to the manner in which the virus spreads, the airborne nature of the virus and need for lockdowns to contain the spread, the aspect of collective social behavior has become more important than ever before. Previous health challenges have been focused on 


\section{International Journal of Social Science and Economic Research}

ISSN: $2455-8834$

Volume:06, Issue:07 "July 2021"

individual behaviors, for example, reducing smoking, improving physical fitness, maintaining good hygiene, etc (Jetten et al, 2020). However, given the contagious nature of COVID-19, whether an individual will become infected is determined not only by their own health behaviors (whether they engage in physical distancing, wash their hands more frequently, wear a mask, etc.), but also by the behaviors of everyone physically close to them (Jetten et al, 2020). This makes COVID-19 quite different from other health challenges. Consequently, tackling COVID19 has required another type of public health campaign (Jetten et al, 2020).

Collective social behavior is especially important in a country like India, where so many types of societies have melded into one. In addition, the dense population and number of people residing in close quarters makes it even more important. The challenge posed by the lack of literacy in the country, different languages, and a large inequality in social class and caste make it important to devise strategies to appeal to the masses and ensure collective behavior to curb the spread of the pandemic, in a culturally sensitive manner. This paper examines the theoretical foundations of collective social behavior, with particular reference to masking as a public health measure. In the Indian context, the paper will review how communities and the government has responded, and the relevance of collective behavior for the effectiveness of public health management. The paper will then conclude with policy recommendations to better instill desirable collective social behavior.

\section{Background}

Many of the behaviors that are known to be effective in reducing the transmission of the virus (e.g., social distancing) involve a tradeoff between self and collective interests, requiring people to bear individual costs to benefit others (Van Lange et al., 2013). Theories on collective behavior have found that cooperation in the event of social dilemmas can be promoted when there are robust institutions present to monitor and enforce the behavior (Jin et al, 2021). People are less likely to cooperate for the benefit of others, when the individual cost to them is high and the benefits to the collective are low (Ledyard, 1995; Jin et al, 2021). Theories of collective social behavior in situations of crisis have been developed from both a sociological and psychological lens. Among the most popular theories is the theory of individual motivation, wherein participation in vital collectivities supplies a sense of meaning through group affirmation and action and raises the member's estimate of his social status (Britannica, n.d). Theories of interaction have been labeled contagion and convergence theories, the former stressing the contagious spread of mood and behaviour, and the latter stressing the convergence of a large number of people with similar predispositions (Britannica, n.d). Another theory which is relevant to crisis situations is the theory of social change, dependent on the changing values and power dynamics in a society. Neil Smelser has provided the most comprehensive theory 


\section{International Journal of Social Science and Economic Research}

ISSN: $2455-8834$

Volume:06, Issue:07 "July 2021"

behind the development of collective social behavior and laid out the presence of six factor, namely: (1) the social structure must be peculiarly conducive to the collective behaviour in question; (2) a group of people must experience strain; (3) a distinctive type of belief must be present to interpret the situation; (4) there must be a precipitating event; (5) the group of people must be mobilized for action on the basis of the belief; and (6) there must be an appropriate interaction between the mobilized group and agencies of social control (Britannica, n.d). Given that the pandemic has put the entire world under a condition of strain, collective social behavior has emerged as an important agent of change to mobilize action among people, enforced by agencies of social control such as respective governments and the World Health Organisation.

Since the advent of the pandemic, there has been no dearth of literature on the benefits of wearing masks and the clear cause and effect relationship between wearing masks and containing the spread. For example, the Center for Disease Control and Prevention in the USA has continually found that wearing a mask protects oneself and those around them, given that even asymptomatic people as well as vaccinated people can be carriers of the virus (CDC, 2021). However, the mixed messaging and lack of political clarity around the necessity to wear masks has seen a lack of effectiveness of the adoption of this measure in different countries (Jarry, 2020). In the USA, this took the form of anti mask protests, primarily by those with a conservative political affiliation due to President Trump and Republican politicians denouncing the benefits of masks, and distorting the scientific conclusions around covid-19, claiming it is no worse than the flu, and even worse that it is a part of a foreign conspiracy (Jarry, 2020). Some people claim not to be against masks per se but against governments (and sometimes businesses) mandating their adoption (Jarry, 2020).

In India, while there were no anti mask protests or movements as in Western countries, there have been challenges in encouraging collective social behavior in wearing masks. This is primarily due to socio-economic conditions and political messaging. In India, a lack of information and general efforts to promote literacy has led to many being unconvinced that there is any real threat posed by asymptomatic people and consequently, no need to wear masks (Srikanth, 2020). In addition, most Indian households do not have the luxury of social distancing or even access to clean water and soap on a regular basis (Srikanth, 2020). Alcohol based hand sanitizers prove to be too expensive. The following section of this paper will further contextualize collective social behavior in the Indian context, and emphasize its relevance in effectively managing public health emergencies. 


\section{International Journal of Social Science and Economic Research}

ISSN: $2455-8834$

Volume:06, Issue:07 "July 2021"

\section{Discussion}

Different communities in India have responded in different ways in terms of Covid related safety measures. This is dependent on socio-economic status, gender, education level, religion and other such factors. While the privileged middle and upper middle classes were able to isolate in the home, adopt social distancing and generally avail of the information needed to wear masks and adopt other measures, even the simplest of measures were out of reach for India's poor (Bansal, 2021). The lockdown saw thousands of migrant workers begin an arduous walk of hundreds of kilometers with their families and meager belongings to reach the security and familiarity of their homes in villages and small towns. This is the largest human displacement that the Indian subcontinent has seen since the India-Pakistan Partition in 1947 (Bansal, 2021). Daily laborers and the poor therefore saw survival as the first priority and adopting covid safety measures as a second priority, even though these factors work in tandem (Bansal, 2021). In addition, mixed messaging from religious leaders and political leaders has led to varying perceptions among social groups. For example, the recent large scale election rallies saw hundreds of thousands of people gathering together without wearing masks and found support from political leaders holding those rallies (Tewari, 2021). In addition, the recent mass religious gathering, the Kumbh Mela drew flak from health experts for allowing a mass gathering without any covid safety norms (Tewari, 2021). Therefore, India's experience has been a mix of a lack of effective messaging from institutional authorities and a lack of societal cooperation and conformity to rules.

There is great relevance and importance for ensuring good collective social behavior in managing pandemics. A survey in India found that while $90 \%$ of respondents were aware of the benefits of using a mask, only $44 \%$ were compliant with all the correct ways of ensuring maximum safety from mask wearing (Alves, 2020). A clear preference for masks emerged among respondents in the higher income groups, with lower income groups largely claiming inconvenience and difficulty as factors for lack of compliance (Alves, 2020). Only 50\% of all respondents wore a mask the entire duration while out of their household, and the youth aged 2635 years did not believe masking made much of a difference (Alves, 2020).

Therefore, it is clear that overall, governmental institutions have failed to enforce good collective social behavior. Drawing from Smelser's theory as mentioned above, there is deviance among the collective for several reasons. Firstly, lower income groups find the cost of engaging in the trade off too high. Secondly, there is not enough interaction between the mobilized group of people and institutional structures which enforce the behaviour. Mixed messaging from the government and messages of defeating the virus have also led to a level of complacence among the populace and authorities, which has led to a disintegration in messaging rather than mobilization. In 


\section{International Journal of Social Science and Economic Research}

ISSN: $2455-8834$

Volume:06, Issue:07 "July 2021"

addition, governmental institutions have not considered the particular social context of India, which has led to an attachment of stigma to those affected with Covid, including Muslims, religious minorities, gender minorities, lower castes, and even healthcare workers. The outbreak of covid-19 has created social stigma and discriminatory behavior towards individuals who are perceived to have any contact with the disease (Bhattacharya, 2020). There have been instances wherein families have refused to cremate the bodies of their relatives who died of covid, discrimination against lower castes and migrant workers, attacking healthcare workers, etc.

Therefore, interventions implemented through an intersectional lens can improve the understanding of the ways in which COVID-19 stigma might be intersecting with gender, race, immigration status, and health status, among others, and improve cooperation among the collective which is an essential element of collective social behavior (Bhattacharya, 2020). Stigma exists beyond scientific understanding of diseases, at all societal levels. This is aided by misinformation and xenophobia during pandemics and it is crucial that policy makers act with urgency to reduce these instances and promote good collective behavior as a consequence (Bhattacharya, 2020).

\section{Conclusion}

It is apparent from the global experience with the pandemic that desirable collective social behavior is a key factor for public policy, and the factors that influence the same must be harnessed in a clear way by policy makers. Using research from the fields of social and behavioral science, it is possible to encourage and enforce practices such as wearing masks. Effective communication strategies should appeal to people's sense of social norms and social value, as well as their predispositions and share beliefs of threat perception (Bavel, 2020). Communication strategies must strike a balance between breaking through optimism bias without inducing excessive feelings of anxiety and dread (Bavel, 2020). Common methods for establishing social norms include comparing people's actions to others, providing positive feedback, and placing messaging where it is most relevant (Henderson, 2020). Governments must also strongly prohibit discrimination and stigmatisation among the populace, as this reduces the sense of shared value, cooperation and a sense of a common positive outcome (Bavel, 2020).

What is also important for the way forward, is an increased study of how various aspects of social and cultural contexts influence the extent and speed of behaviour change, including social inequality, the value of effective social networks, and political polarization and the effect of statements from political leaders (Henderson, 2020; Bavel, 2020). The pandemic has also underscored the requirement for effective and accessible scientific communication which does not exclude those with lesser educational levels (Henderson, 2020; Bavel, 2020). 
International Journal of Social Science and Economic Research

ISSN: 2455-8834

Volume:06, Issue:07 "July 2021"

\section{References}

Alves, G, (2020), 'Survey says 90\% Indians aware, but only 44\% wearing a mask; discomfort key reason for non-compliance', The Economic Times, https://economictimes.indiatimes.com/magazines/panache/survey-says-90-indians-aware-butonly-44-wearing-a-mask-discomfort-key-reason-for-noncompliance/articleshow/78315069.cms?from $=\mathrm{mdr}$

Bansal, P. (2021), 'Big and Small Stories from India in the COVID19 Plot: Directions for a 'Post Coronial' Psychology', Integrative Psychological and Behavioral Science, 55 47-72, https://doi.org/10.1007/s12124-020-09585-6

Bavel, J, (2020), 'Using social and behavioural science to support COVID-19 pandemic response', Nature Human Behavior, 4, 460-471, https://www.nature.com/articles/s41562-020$\underline{0884-\mathrm{Z}}$

Bhattacharya, P, (2020), 'The "Untold" Side of COVID-19: Social Stigma and Its Consequences in India', Indian Journal of Psychological Medicine, https://journals.sagepub.com/doi/full/10.1177/0253717620935578

Brittanica, (n.d), 'Theories of Collective Behavior', https://www.britannica.com/science/collective-behaviour/Theories-of-collective-behaviour

CDC, (2021), 'Morbidity and Mortality Weekly Report', https://www.cdc.gov/mmwr/volumes/70/wr/mm7007e1.htm?s_cid=mm7007e1_x

Henderson, E, (2020), 'Social norms can influence mask use behavior', News Medical Life Sciences, https://www.news-medical.net/news/20201028/Social-norms-can-influence-mask-usebehavior.aspx

Jarry, J, (2020), 'Why Some People Choose Not to Wear a Mask', McGill Office for Science and Society, https://www.mcgill.ca/oss/article/covid-19-health/why-some-people-choose-not-wear$\underline{\text { mask }}$

Jetten, J, et al, (2020), 'Collective Behavior Change is the Only Way We Can Stop the Spread of COVID-19', SagePub Blog, https://group.sagepub.com/blog/social-science-impact/collectivebehavior-change-is-the-only-way-we-can-stop-the-spread-of-covid-19 
International Journal of Social Science and Economic Research

ISSN: 2455-8834

Volume:06, Issue:07 "July 2021"

Jin, S, et al (2021), 'Intergenerational conflicts of interest and prosocial behavior during the COVID-19 pandemic', Personality and Individual Differences, Volume 171, March 2021, https://www.sciencedirect.com/science/article/pii/S0191886920307261

Ledyard, JO, (1995), Public goods: A survey of experimental research, In J.H. Kagel, A.E. Roth (Eds.), The handbook of experimental economics, Princeton University Press (1995), pp. 111194, https://resolver.caltech.edu/CaltechAUTHORS:20170823-160736011

Srikanth, SN (2020), 'The pandemic and the challenge of behaviour change', The Hindu, https://www.thehindu.com/opinion/op-ed/the-pandemic-and-the-challenge-of-behaviourchange/article31596370.ece

Tewari, R, (2021), 'Poll rallies to Kumbh Mela - Modi-Shah's conscience must take a look at latest Covid surge', The Print, https://theprint.in/opinion/politricks/poll-rallies-to-kumbh-melamodi-shahs-conscience-must-take-a-look-at-latest-covid-surge/639526/

Van Lange, J. et al, (2013), 'The psychology of social dilemmas: A review', Organizational Behavior and Human Decision Processes, 120 (2), pp. 125 141, 10.1016/j.obhdp.2012.11.003

Worldometer covid-19 Tracker, (2021), https://www.worldometers.info/coronavirus/ 